\title{
Addressing the New Global Threat of Xylella fastidiosa
}

\author{
R. P. P. Almeida, ${ }^{1, \dagger}$ L. De La Fuente, ${ }^{2}$ R. Koebnik, ${ }^{3}$ J. R. S. Lopes, ${ }^{4}$ S. Parnell, ${ }^{5}$ and H. Scherm 6
}

${ }^{1}$ Department of Environmental Science, Policy \& Management, University of California, Berkeley; ${ }^{2}$ Department of Entomology \& Plant Pathology, Auburn University, Auburn, AL; ${ }^{3}$ IRD, Cirad, Universite de Montpellier, IPME, Montpellier, France; ${ }^{4}$ Department of Entomology and Acarology, Luiz de Queiroz College of Agriculture (Esalq), University of São Paulo, Piracicaba, SP, Brazil; ${ }^{5}$ School of Environment \& Life Sciences, University of Salford, Manchester, UK; and 'DDepartment of Plant Pathology, University of Georgia, Athens 30605.

Xylella fastidiosa is one of the most important threats to plant health worldwide. This bacterial pathogen has a long history, causing disease in the Americas on a range of agricultural crops and trees, with severe economic repercussions particularly on grapevine and citrus. In Europe, $X$. fastidiosa was detected for the first time in 2013 in association with a severe disease affecting olive trees in southern Italy. Subsequent mandatory surveys throughout Europe led to discoveries in France and Spain in various host species and environments. Detection of additional introductions of $X$. fastidiosa continue to be reported from Europe, for example from northern Italy in late 2018. These events are leading to a sea change in research, monitoring and management efforts as exemplified by the articles in this Focus Issue. X. fastidiosa is part of complex pathosystems together with hosts and vectors. Although certain $X$. fastidiosa subspecies and environments have been well studied, particularly those that pertain to established disease in North and South America, this represents only a fraction of the existing genetic, epidemiological, and ecological diversity. This Focus Issue highlights some of the key challenges that must be overcome to address this new global threat, recent advances in understanding the pathosystem, and steps toward improved disease control. It brings together the broad research themes needed to address the global threat of $X$. fastidiosa, encompassing topics from host susceptibility and resistance, genome sequencing, detection methods, transmission by vectors, epidemiological drivers, chemical and biological control, to public databases and social sciences. Open communication and collaboration among scientists, stakeholders, and the general public from different parts of the world will pave the path to novel ideas to understand and combat this pathogen.

In October 2013 X. fastidiosa was first reported in Italy, associated with dying olive trees in the southern region of Apulia (Saponari et al. 2019); this was the first report of the bacterium causing an epidemic disease in the Old World. Five years have passed since that account, during which $X$. fastidiosa has emerged from a pathogen important to a handful of agricultural crops and trees in specific regions of the Americas to a major global threat to food production, forestry, and landscapes. A new infusion of funding for research, monitoring, and management is expected to occur worldwide, particularly in Europe where the pathogen is subject to intensive surveillance and eradication efforts, as is noted in the perspective article by Lindow (2019) in this issue. This will lead to a new phase of scientific discoveries and insights into the biology of $X$. fastidiosa at the global scale. Indeed, while the United States and Brazil have dominated the scientific literature on $X$. fastidiosa up to now, the papers in this Focus Issue reflect that the expansion of interest to other regions of the world has already started to bear fruit; among the 20 articles included here, 9 originated from research in Europe, 7 from the United States, and 4 from Brazil.

†Corresponding author: Rodrigo P. P. Almeida;

E-mail: rodrigoalmeida@berkeley.edu

(c) 2019 The American Phytopathological Society
While funding will help to address the new global threat of $X$. fastidiosa, the challenges are complex, as summarized by Saponari et al. (2019) for the current epidemic of olive quick decline in Italy. This Focus Issue includes contributions representing some of the key research topics that must be addressed to understand the outcome of bacteria-plant-insect interactions that ultimately lead to disease, as highlighted by Jeger and Bragard (2019). Indeed, while research in the Americas during the past two decades has led to important advances in our understanding of $X$. fastidiosa biology, ecology, and evolution, there are still significant knowledge gaps as well as room for innovation for development of tools to study this pathosystem. For example, attempts have been made to use Arabidopsis as a host of $X$. fastidiosa in the past, but here Pereira et al. (2019) demonstrate that ecotype Col-0 is systemically infected by this bacterium, opening the door for Arabidopsis to be used as a model to answer fundamental questions on host-pathogen interactions. While exciting, this finding illustrates how much still remains to be studied and discovered about this pathogen.

The large majority of $X$. fastidiosa research has used two strains, $X$. fastidiosa subsp. pauca '9a5c' from citrus in Brazil and $X$. fastidiosa subsp. fastidiosa 'Temecula1' from grapevine in the United States. Knowledge from these two well-studied biological systems appears to be transferable to other X. fastidiosa genotypes/ diseases, as illustrated by Esteves et al. (2019) in a report that demonstrates that an in vitro protocol used to provide bacterial cells to insects is transferable from Temeculal to a distantly related phylogenetic clade from citrus-infecting $X$. fastidiosa. Nevertheless, these two strains represent a miniscule fraction of the known $X$. fastidiosa genetic diversity; this is of concern as new genotypes of $X$. fastidios $a$ are now constantly reported from the Americas and Europe, such as those from olive trees in Brazil reported by Safady et al. (2019). The question of how significant the findings with a limited number of strains are in relation to $X$. fastidiosa as a species has become particularly relevant to the scientific community. This is especially important since the basis of host adaptation in $X$. fastidiosa is still unknown, and the study by Nunney et al. (2019) exemplifies how little we know about the relationship between bacterial genotype and host range.

Due to the current interest in Europe and elsewhere in pathogen quarantine and containment that relies heavily in surveys and diagnosis, there is an expectation that research will address knowledge gaps in those areas. Difficulties in plant diagnosis are illustrated by Chen et al. (2019), showing the need to adapt molecular techniques for different plant hosts. Plant physiological responses may be an alternative to survey for $X$. fastidios $a$ presence compared with currently used detection methods, as suggested by Nicoli et al. (2019). Martinetti and Soubeyrand (2019) used a combination of machine learning and network analyses to understand disease drivers as well as generate risk maps. However, while efforts focusing on containment are necessary, in areas where $X$. fastidiosa is now established, such as several regions in the Mediterranean Basin, research should also focus on understanding disease epidemiology and drivers behind epidemics. As shown for Pierce's disease of grapevine in California by Daugherty and 
Almeida (2019), even well-studied systems still lack quantitative understanding of the various biotic and abiotic factors driving diseases caused by $X$. fastidiosa. This will become increasingly important where $X$. fastidiosa diseases are emerging, as these represent new regions of the globe with distinct vectors, plants, landscapes, and social-cultural contexts. Some knowledge on $X$. fastidiosa has been shown to be transferable, but substantial differences in epidemiology have also been demonstrated for ecological conditions initially considered to be highly similar.

While extensive research on controlling infections by $X$. fastidiosa, and hopefully curing plants from infection, has been performed in the United States and Brazil, the ultimate goal of disease control is critical and continues to be pursued aggressively. Three lines of research on this matter are represented in this Focus Issue. First, although efforts to evaluate a wide range of chemical molecules to control infections have been conducted previously, here Zhang et al. (2019) pursue additional in planta tests, which are often lacking from such studies and are key to success since a wide range of molecules can affect $X$. fastidiosa viability in vitro. Baccari et al. (2019) present their ongoing work on biological control of Pierce's disease of grapevine using a Paraburkholderia phytofirmans strain; this is a particularly stimulating advancement, given that the strain appears to be effective in suppressing disease symptoms even when sprayed on plants by inducing host resistance pathways. Lastly, Mauricio et al. (2019) report on a long-term effort to understand plant resistance to $X$. fastidiosa infections of sweet orange trees in Brazil; resistance is indeed a highly desirable strategy to manage $X$. fastidiosa diseases.

In addition to studies to control $X$. fastidiosa, there are also novel types of data, curated databases, and genomic sequences that should be incorporated into efforts to understand and manage diseases. Making those publicly available in a timely fashion is expected from the scientific community, and colleagues contributed with genome sequences of novel strains from Spain (Giampetruzzi et al. 2019; Gomila et al. 2019). Interestingly the use of next-generation sequencing revealed detection of additional plasmids in X. fastidiosa (Giampetruzzi et al. 2019; Van Horn et al. 2019), although the function of these plasmids in the infection process remains largely unknown. Other very useful public resources presented here include a manually curated database of $X$. fastidiosa host plants (Delbianco et al. 2019) and a novel resource to monitor social media in the context of emerging plant pests (Ferilli et al. 2019).

There are several research threads of relevance to $X$. fastidiosa that need more attention in the future, such as fundamental understanding of host (both insect and plant) adaptation and evolution of the bacterium. Significant knowledge gaps also exist regarding insect vectors. While there is a considerable body of literature about sharpshooter leafhopper vectors in the Americas, the main vectors in Europe are spittlebugs, which represent a distantly related group of xylem-sap feeders with distinct morphological and bioecological characteristics. We have known that spittlebugs are vectors of $X$. fastidiosa since 1950, but their relative epidemiological importance in the Americas is thought to be minimal; hence, these insects are understudied in this context. Although understanding the role of spittlebugs in spreading $X$. fastidiosa in Europe will be facilitated by existing knowledge on other vector taxa, the situation is complex in that the ecology of spittlebugs as vectors in relation to disease is likely to vary depending on location, flora, and landscape.

A major gap that is becoming increasingly apparent, and where our lack of expertise and understanding is glaring, is related to the dearth of efforts incorporating social sciences and the humanities into phytopathological research and outreach. Ultimately policy decisions, particularly for emerging diseases, represent political compromises that incorporate the needs and desires of stakeholders. Understanding how stakeholders respond to environmental challenges, here represented by an emerging plant pathogen, is key for the development of effective policy strategies. Colella et al. (2019) discuss how academic and public discourse on the olive quick decline epidemic in southern Italy evolved in light of novel scientific information, how new information was interpreted by different groups, and ultimately how a complex network of actors have shaped responses by governmental agencies. Social sciences and the humanities represent a clear and obvious new frontier in plant pathology, one that the community must embrace.

We hope that this Focus Issue highlights current research efforts on $X$. fastidiosa and promotes new ideas and concepts for future efforts. Open communication and collaboration among scientists, stakeholders and the general public from different parts of the world will pave the path to novel ideas to understand and combat this difficult pathogen. As the breadth and depth of research on $X$. fastidiosa is increasing globally, we look forward to more permanent solutions being developed with enhanced research funding and focus on novel questions by scientists from outside the $X$. fastidiosa mainstream joining the research effort.

\section{ACKNOWLEDGMENTS}

We thank Senior Editors Clive Bock and Peter Ojiambo for handling two manuscripts for this Focus Issue.

\section{LITERATURE CITED}

Baccari, C., Antonova, E., and Lindow, S. 2019. Biological control of Pierce's disease of grape by an endophytic bacterium. Phytopathology 109:109: 248-256.

Chen, C., Bock, C. H., and Brannen, P. M. 2019. Novel primers and sampling for PCR detection of Xylella fastidiosa in peach. Phytopathology 109: 307-317.

Colella, C., Carradore, R., and Cerroni, A. 2019. Problem setting and problem solving in the case of olive quick decline syndrome in Apulia, Italy: A sociological approach. Phytopathology 109:187-199.

Daugherty, M. P., and Almeida, R. P. P. 2019. Understanding how an invasive vector drives Pierce's disease epidemics: Seasonality and vine-to-vine spread. Phytopathology 109:277-285.

Delbianco, A., Czwienczek, E., Pautasso, M., Kozelska, S., Monguidi, M., and Stancanelli, G. 2019. A new resource for research and risk analysis: The updated European Food Safety Authority database of Xylella spp. host plant species. Phytopathology 109:213-215.

Esteves, M. B., Kleina, H. T., Sales, T. M., Oliveira, T. P., de Lara, I. A. R., Almeida, R. P. P., Coletta-Filho, H. D., and Lopes, J. R. S. 2019. Transmission efficiency of Xylella fastidiosa subsp. pauca sequence types by sharpshooter vectors after in vitro acquisition. Phytopathology 109:286-293.

Ferilli, F., Stancanelli, G., Linge, J. P., and Mannino, M. R. 2019. A new online resource to monitor new or emerging plant pests: MEDISYS media monitoring and the case of Xylella fastidiosa. Phytopathology 109:216-218.

Giampetruzzi, A., Velasco-Amo, M. P., Marco-Noales, E., Montes-Borrego, M., Román-Écija, M., Navarro, I., Monterde, A., Barbé, S., Almeida, R. P. P., Saldarelli, P., Saponari, M., Montilon, V., Savino, V. N., Boscia, D., and Landa, B. B. 2019. Draft genome resources of two strains ("ESVL" and "IVIA5901") of Xylella fastidiosa associated with almond leaf scorch disease in Alicante, Spain. Phytopathology 109:219-221.

Gomila, M., Moralejo, E., Busquets, A., Segui, G., Olmo, D., Nieto, A., Juan, A., and Lalucat, J. 2019. Draft genome resources of two strains of Xylella fastidiosa XYL1732/17 and XYL2055/17 isolated from Mallorca vineyards. Phytopathology 109:222-224.

Jeger, M., and Bragard, C. 2019. The epidemiology of Xylella fastidiosa; A perspective on current knowledge and framework to investigate plant host-vector-pathogen interactions. Phytopathology 109:200-209.

Lindow, S. 2019. Money matters: Fueling rapid recent insight into Xylella fastidiosa-An important and expanding global pathogen. Phytopathology 109:210-212.

Martinetti, D., and Soubeyrand, S. 2019. Identifying lookouts for epidemiosurveillance: Application to the emergence of Xylella fastidiosa in France. Phytopathology 109:265-276.

Mauricio, F. N., Soratto, T. A. T., Diogo, J. A., Camargo, R. B., De Souza, A. A., Coletta-Filho, H. D., Silva, J. A. A., Medeiros, A. H., Machado, M. A., and Cristofani-Yaly, M. 2019. Analysis of defense-related gene expression in citrus hybrids infected by Xylella fastidiosa. Phytopathology 109:301-306.

Nicolì, F., Negro, C., Nutricati, E., Vergine, M., Aprile, A., Sabella, E., Damiano, G., De Bellis, L., and Luvisi, A. 2019. Accumulation of azelaic acid in Xylella fastidiosa-infected olive trees: A mobile metabolite for health screening. Phytopathology 109:318-325. 
Nunney, L., Azad, H., and Stouthamer, R. 2019. An experimental test of the host-plant range of nonrecombinant strains of North American Xylella fastidiosa subsp. multiplex. Phytopathology 109:294-300.

Pereira, W. E. L., Ferreira, C. B., Caserta, R., Melotto, M., and de Souza, A. A. 2019. Xylella fastidiosa subsp. pauca and fastidiosa colonize Arabidopsis systemically and induce anthocyanin accumulation in infected leaves. Phytopathology 109:225-232.

Safady, N. G., Lopes, J. R. S., Francisco, C. S., and Coletta-Filho, H. D. 2019. Distribution and genetic diversity of Xylella fastidiosa subsp. pauca associated with olive quick syndrome symptoms in Southeastern Brazil. Phytopathology 109:257-264.
Saponari, M., Giampetruzzi, A., Loconsole, G., Boscia, D., and Saldarelli, P. 2019. Xylella fastidiosa in olive in Apulia: Where we stand. Phytopathology 109:175-186.

Van Horn, C., Wu, F., Zheng, Z., Dai, Z., and Chen, J. 2019. Detection of a single-copy plasmid, pXFSL21 in Xylella fastidiosa strain Stag's Leap with two toxin-antitoxin systems using next-generation sequencing. Phytopathology 109:240-247.

Zhang, S., Jain, M., Fleites, L. A., Rayside, P. A., and Gabriel, D. W. 2019. Identification and characterization of menadione and benzethonium chloride as potential treatments of Pierce's disease of grapevines. Phytopathology 109:233-239. 